\section{Cuidando de idosos altamente dependentes na comunidade: um estudo sobre cuidadores familiares principais}

\author{
Caring for the highly dependent elderly in the \\ community: a study on the main family caregivers
}

Teresinha Mello da Silveira 1,2

Célia Pereira Caldas 2,3

Terezinha Féres Carneiro 4

\footnotetext{
1 Instituto de Psicologia, Universidade do Estado do Rio de Janeiro, Rio de Janeiro, Brasil.

2 Universidade Aberta da

Terceira Idade, Universidade do Estado do Rio de Janeiro, Rio de Janeiro, Brasil.

3 Faculdade de Enfermagem, Universidade do Estado do Rio de Janeiro, Rio de Janeiro.

${ }^{4}$ Departamento de Psicologia, Pontifícia Universidade Católica do Rio de Janeiro, Rio de Janeiro, Brasil.

Correspondência C. P. Caldas Universidade Aberta da Terceira Idade, Universidade do Estado do Rio de Janeiro. Rua São Francisco Xavier 524,10 o andar, bloco $F$, sala 10.150 , Rio de Janeiro, $R J$ 20559-900, Brasil. ccaldas@uerj.br
}

\begin{abstract}
This study aims to contribute to a better understanding of the main family caregivers of highly dependent elderly. Performed in a geriatric outpatient unit, the study used a content analysis methodology, and data were collected with interviews and 14 group sessions with 24 subjects. The following categories emerged: denial versus acceptance of the disease before and after diagnosis; how and why the main caregiver assumes this role; caregiver's characteristics; caregiver's experiences; meanings ascribed to care-giving; history of the caregiver's relationship to the elder before the disease; caregiver/elder relationship since onset of the disease; changes in the caregiver's life; changes in the family; and causes for the appearance of the disease. In conclusion, there are three dimensions in the target issue: (1) implications of the legacies, multi-generational transmission, repetition of the patterns, and myths and beliefs in each family system; (2) seniors as active participants in the care-giving decision; and (3) the support group as a key resource for the family.
\end{abstract}

Aged; Caregivers; Family

\section{Introdução}

Com o aumento da expectativa de vida, aumenta também a possibilidade de o idoso ser acometido por doenças de ordens diversas. O presente estudo trata de uma patologia cujo maior fator de risco é a idade avançada - a demência. Os dados epidemiológicos indicam que a síndrome demencial tem sua incidência relacionada ao envelhecimento, acometendo de $5 \%$ a $10 \%$ das pessoas acima de 65 anos, $20 \%$ das pessoas de mais de 80 anos, podendo chegar a $47 \%$ dos idosos com mais de 85 anos 1 .

A demência é uma síndrome que compromete o raciocínio, a memória, a percepção, a atenção, a capacidade de conhecer e reconhecer, a linguagem e a personalidade. Ela torna o seu portador cada vez mais dependente, por se tratar de um quadro progressivo e irreversível. As incapacidades do doente limitam-no inicialmente e, por fim, impedem-no de realizar as mais simples tarefas da vida diária. Além do mais, dificultam cada vez mais o relacionamento com amigos, com o trabalho e com a família 2.

Do ponto de vista médico, até o momento, pouco se pode fazer no sentido de impedir ou reverter o quadro, conseguindo-se, no máximo, retardar a evolução da doença, quando o diagnóstico é feito na fase mais inicial. Com a evolução da doença, a pessoa torna-se progressivamente dependente de cuidados familiares. 
Pode acontecer de a família ficar desorientada, ocorrendo paralisações e/ou conflitos no seio familiar até ela se reorganizar, surgindo do grupo um ou mais membros dispostos a cuidar. Nessas ocasiões, a equipe de profissionais procura explicar e esclarecer a necessidade de o paciente ser cuidado e se coloca à disposição para dar o suporte necessário, tanto para o familiar enfermo, quanto para as pessoas que vão cuidar dele.

Comumente não há indicação de institucionalizar o idoso. Portanto, é fundamental que a família e a comunidade aprendam a conviver e lidar com esta realidade: a existência de pessoas em processo demencial.

Para além da assistência e da saúde, as múltiplas tarefas práticas, a atenção e o carinho dispensados ao doente, os fatores econômicos, o uso de transportes coletivos, a moradia, entre outros, devem ser considerados primordialmente no caso dos idosos doentes. Todos esses fatores oneram de diferentes maneiras os familiares, responsáveis primeiros pelos cuidados. Desse modo, podemos avaliar a grandeza da problemática e justificar não só nossa preocupação com o paciente demenciado, mas também com as pessoas que lidam com ele.

É nesse contexto que, na prática assistencial, inserem-se os grupos de suporte aos familiares de pacientes com alta dependência. Esses grupos têm como meta ajudar os cuidadores a terem um envolvimento construtivo com o parente que adoeceu, sem abdicar de sua vida pessoal.

O presente estudo tem como objetivo geral contribuir com subsídios teóricos e práticos para uma melhor compreensão de quem é o cuidador principal, como surge e como é construída sua subjetividade. Como objetivos específicos, buscamos verificar que injunções estão envolvidas na relação cuidador principal/familiar com síndrome demencial e oferecer recursos para os profissionais que trabalham com famílias que têm idosos e/ou com cuidadores familiares em instituição de saúde.

\section{Método}

O estudo foi realizado no Núcleo de Atenção ao Idoso (NAI), unidade ambulatorial da Universidade Aberta da Terceira Idade, Universidade do Estado do Rio de Janeiro (UNATI/UERJ). Essa unidade conta com um grupo de suporte aos familiares cuidadores de pacientes com alto nível de dependência, que é coordenado por uma enfermeira, um médico e uma psicóloga, reunindo-se reúne semanalmente. Os sujeitos deste estudo são os participantes desse grupo.
Trata-se de um estudo transversal, com a utilização de método qualitativo para análise de conteúdo ${ }^{3}$. A coleta de informações se deu por meio de entrevista realizada com auxílio de roteiro semi-estruturado e em 14 sessões do grupo de suporte. As entrevistas e as sessões do grupo foram gravadas, mediante autorização e assinatura do termo de consentimento livre e esclarecido, sendo posteriormente transcritas. A pesquisa obedeceu à Resolução 196/96 e foi apreciada pelo Comitê de Ética em Pesquisa da UNATI/UERJ.

Os sujeitos do estudo foram os 24 cuidadores principais de idosos com diagnóstico de síndrome demencial, participantes do grupo de suporte, dos quais sete são homens e 17 são mulheres. A idade variou entre 28 e 89 anos: 11 entre 28 e 49 anos e 13 entre 50 e 89 anos. Quanto ao grau de parentesco, três são esposas; quatro são maridos; três são filhos; nove são filhas (uma é adotiva); uma é neta; uma é nora; duas são irmãs e uma é sobrinha. Dez cuidadores trabalham fora e 14 não trabalham; 12 contam com a ajuda de acompanhantes profissionais. A renda familiar varia entre 2 e 25 salários mínimos: 14 cuidadores têm renda entre 2 e 10 salários; dez têm renda entre 12 e 25 salários. Uma cuidadora é analfabeta; sete completaram o ensino fundamental; quatro têm ensino médio e 12 têm nível universitário.

\section{Resultados e discussão}

Utilizando o método de análise de conteúdo 3 , fizemos uma primeira leitura completa do material transcrito. Depois relemos cada entrevista, registrando a freqüência de surgimento das unidades de registro. A dinâmica própria do grupo de suporte ofereceu dados que permitiram verificar a relevância dos temas expressos nas entrevistas. Pelos dados colhidos das entrevistas e nos grupos, verificamos em que contextos surgiam os temas, emergindo deles as seguintes categorias que serão discutidas a seguir: negação versus aceitação da doença antes e depois do diagnóstico; como e por que surge o cuidador principal; características do cuidador; vivências do cuidador; significados do ato de cuidar; história do relacionamento do cuidador com o idoso antes da doença; relacionamento cuidador/idoso após a doença; mudanças na vida do cuidador principal; mudanças na família; causas para o surgimento da doença. 
Negação versus aceitação da doença antes e depois do diagnóstico

A comunicação do diagnóstico sempre causa impacto nos familiares. Muitos cuidadores ficam surpresos com a informação e esperam ou que o diagnóstico esteja errado e exista alguma possibilidade de reversão, ou que ocorra uma espécie de "milagre". Dos 24 entrevistados, 21 se recusaram inicialmente a aceitar a doença ao serem informados do diagnóstico.

“Eu não acreditei, eu perguntei: Dr., eu posso acreditar no que o Sr. está me dizendo? Não é possível. Ele está tão sadio!" (Dilma, esposa, 63 anos).

Apesar de no início ser difícil aceitar ou mesmo perceber os sintomas, com a evolução da doença as pessoas passam paulatinamente a aceitar o quadro, embora essa aceitação não seja total em nenhum dos entrevistados.

As sessões gravadas do grupo de suporte mostram que, na população investigada, a participação no grupo colabora para que a doença seja aceita mais facilmente, porque não só outros membros partilham da mesma problemática e a doença não fica tão estigmatizada, como também as intervenções dos coordenadores facilitam a aceitação do quadro patológico, objetivando um melhor relacionamento entre o cuidador e o sujeito cuidado.

"É sempre difícil você aceitar que a sua mãe está assim, não é? Eu cada vez chamo mais gente para vir para cá. Não tem problema, não é? É difícil, eu ainda acho difícil, mas eu estou muito mais feliz. Eu estou aceitando muito melhor!" (Geórgia, filha, 48 anos).

\section{Como e por que surge o cuidador principal}

Os entrevistados alegam diferentes motivos para estarem no lugar de cuidador principal.

Os cônjuges alegam que têm de cuidar. Mostraram-se surpresos com a pergunta que fizemos e entendemos, por diversos indícios nos relatos, que eles cuidam em decorrência do acordo que fizeram, no casamento, de um cuidar do outro. Em seu relato identificamos os contratos, as promessas feitas no altar por ocasião do matrimônio e as marcas de uma época em que a maioria dos casais se mantinha junto até a morte 4.

"Então eu procedi em termos da nossa situação de marido e mulher, quer dizer, um cuidando do outro (...) Em decorrência da ligação que tinha com ela, automaticamente surgiu a questão da pessoa cuidadora, não por ser a minha mulher, mas uma questão normal de cuidados, de um tratamento (...) É uma troca que existe no casal, embora meus filhos sempre procurem ajudar" (Antônio, marido, 78 anos).

Os filhos justificam-se pelo lugar que ocupam na família. Um porque é o filho mais velho, outro porque é o líder, outro porque é solteiro, uma porque é a filha mais nova, outros porque foram abandonados. Constatamos que o conflito em torno de quem vai cuidar ocorre mais entre os filhos, visto que os esposos sentem-se na obrigação de cuidar. Contudo, não observamos grandes dificuldades no surgimento do cuidador principal entre os sujeitos entrevistados. Somente uma filha, uma nora e uma irmã tiveram um outro parente cuidando antes delas, mas todas três não são contra o papel que hoje assumem. Os outros, embora reclamando por vezes da falta de apoio dos parentes, tornaram-se cuidadores principais desde o início.

Não observamos, entre os entrevistados, que algum deles tenha se tornado cuidador principal por falta de opção. Ser cuidador principal implica um processo que envolve todo o sistema familiar, desta maneira existe todo um movimento na família que vai influir na decisão de quem vai cuidar. Os entrevistados acham que eles é que teriam que cuidar. Não importando por que razão, em todas as entrevistas constatamos as dívidas de reciprocidade, alguns legados, transmissões geracionais, os mitos, as regras, as características comuns ao cuidador e os acordos implícitos 5,6.

Constatamos que o papel de cuidador é construído no relacionamento, com a influência de diversos fatores referentes à história familiar. Dentre os entrevistados, vinte sabiam que ocupariam esse lugar e passaram a cuidar tão logo o familiar precisou de atenção. Isso indica que, de alguma forma, esse papel já estava imaginado ou predeterminado. Ademais, existe uma tendência de os padrões familiares se repetirem em virtude das transmissões geracionais 6,7 . Não só as expectativas, mas também os conflitos são transmitidos multigeracionalmente 5 .

"Na nossa família é sempre o mais velho que cuida. Minha mãe é a mais velha e cuidou da minha avó e eu já vejo na minha filha todo o jeitinho para cuidar. Ela é muito minha amiga, me ouve, me compreende, sempre foi acostumada com velhinhos..." (Luíza, nora, 37 anos).

Dez entrevistados (não cônjuges) disseram que os familiares cuidados os elegeram como cuidadores. Esses participantes corroboram a hipótese de que a escolha é mútua, principalmente se levarmos em consideração que, além deles, os sete cônjuges entrevistados, acham que um deve cuidar do outro. Estes dados são bastante significativos, mas carecem de estudos transgeracionais mais aprofundados. 
“Eu sei que seria eu, foi uma escolha dela. Minha irmã no domingo até falou: 'Ah! É por isso, não é? Você quer que ela fique com você porque você é muito paparicada. A comidinha que você gosta, o suquinho'..." (Cibele, filha, 47 anos).

Alguns sujeitos afirmam que nunca foi conversado em família sobre quem iria cuidar. Constatamos a combinação de elementos familiares, situacionais, de personalidade e sócio-culturais influindo no surgimento do cuidador principal 8 .

No grupo, essa categoria emergiu nos momentos em que os participantes relatavam como decidiram ser cuidadores, o que aconteceu na família para o familiar tornar-se cuidador principal, a preferência do familiar sobre quem iria cuidar. Observamos que, na tentativa de compreender melhor por que eles estão neste papel, este tema muitas vezes vem sob a forma de pergunta.

\section{Características do cuidador}

Nesta categoria verificamos que a maior parte dos cuidadores é de mulheres, o que reflete um dado da nossa cultura 9,10.

As entrevistas mostraram que 16 cuidadores são pessoas decididas, que buscam solucionar problemas, que fazem muitas coisas ao mesmo tempo e que se acham as melhores naquilo que fazem. Essas características ficam mais evidentes nas mulheres.

"Porque é assim, a minha mãe sempre achou que eu sabia me virar melhor. É porque eu sou assim, se eu preciso de uma coisa e não posso ter, eu vou me virar, mas vou conseguir ter. Eu já te disse que eu sou uma lutadora, não é?" (Regina, filha, 51 anos).

Dos sujeitos entrevistados, 15 cuidadores não pedem ajuda por acharem que não devem, por acharem que sabem cuidar melhor, ou por acharem que os outros deveriam saber que têm que ajudar 9 .

“Não, eu não vou pedir. Eu não vou acreditar que alguém vai cuidar dela direito, do jeito que ela gosta, do jeito que ela quer. Eu a conheço, eu sei a hora certa de dar uma bronquinha, entendeu? Ela caminha, fala, faz as coisas porque eu forço..." (Olívia, sobrinha, 55 anos).

Dezessete entrevistados são pessoas que se dizem e/ou demonstram de diversas formas que são prestativas, disponíveis, solidárias. Percebemos esses aspectos também quando convidamos os cuidadores para participar das entrevistas. O esforço para fornecer dados, a prontidão em atender à solicitação, o interesse em participar, corroboram o que eles falam e demonstram no ato de cuidar. As sessões de gru- po também deixam transparecer esses atributos utilizados para ajudar os companheiros. Dois dos sujeitos entrevistados se disseram submissos e alegam que cuidam porque sempre se submeteram ao autoritarismo da pessoa cuidada.

"Até hoje parece que eu a ouço dando ordens na minha vida e eu tenho que cumprir. E olha que eu já estou bem melhor..." (Cibele, filha, 47 anos).

Ser capaz de perceber o que o outro precisa ter sensibilidade - é uma característica que foi mais identificada nos relatos do que explicitada pelos cuidadores.

"Eu já sei quando ela quer ir ao banheiro, quando ela quer comer, a posição do corpo dela me diz se ela está tristinha. Às vezes ela quer me enganar, mas eu olho para ela e vejo logo: 'O que que é isso, tia? O que que você pegou aí?' Eu já sei que é doce, e ela não pode comer..." (Olívia, sobrinha, 55 anos).

As características do cuidador principal tornam-se evidentes não só no que é falado, como nas atitudes no grupo. No intercâmbio entre os componentes, podemos observar: habilidades, sensibilidade, empatia. São características que parecem fazer parte da personalidade de quem cuida, mas tomam mais expressão no ato de cuidar. Sendo assim, cuidar também é uma maneira de se auto-realizar. A auto-realização é abordada pelos entrevistados como uma forma de dar significado ao ato de cuidar.

\section{Vivências do cuidador}

A análise desta categoria nos permitiu verificar os sentimentos, os estados de espírito e a forma como os cuidadores experimentam internamente e expressam o ato de cuidar. Entre os sujeitos investigados, cuidar de um familiar que demenciou mobiliza muitos sentimentos antagônicos em curto espaço de tempo: amor e raiva, paciência e intolerância, carinho, tristeza, irritação, desânimo, pena, revolta, insegurança, negativismo, solidão, dúvida quanto aos cuidados, medo de ficar doente também, medo de o paciente estar sofrendo, medo de o paciente morrer. Dessa maneira, tanto nas entrevistas, quanto nas sessões de grupo, seus relatos são ora muito otimistas, ora muito pessimistas.

"É um sofrimento ver minha mãe decair. Encarar essa decadência, não sei... é o lado triste, tomar consciência que ela pode morrer, que eu posso morrer. Eu nunca tive esse cuidado com a vida, eu acho que ainda não estou preparada, mas eu pensei que minha mãe pode morrer e fiquei com muito medo" (Geórgia, filha, 48 anos).

Contudo o sentimento mais comum foi a culpa, relatada e/ou expressa por 21 sujeitos. 
Todos disseram que se sentem muito culpados, seja pelo sofrimento do paciente, seja por não conseguir cuidar com tranqüilidade. As pessoas entrevistadas estão muito presas aos conceitos de certo e de errado, revelando sentimentos de dívida e/ou de culpa para com a pessoa cuidada. Essa avaliação é freqüente quando uma pessoa tem que tomar conta de alguém. Quando se julga falhando em alguma coisa, a pessoa sente-se culpada. A culpa relacionada a parentes próximos pode ser resultado da eclosão de sentimentos negativos em relação ao paciente que agora está mais fragilizado. Pode ser, ainda, decorrente de questões não resolvidas no relacionamento do cuidador com a pessoa cuidada, anteriores à doença.

Os cuidadores relatam cansaço, desgaste, revolta, depressão e somatizações. São pessoas, na sua grande maioria, com mais de quarenta anos, e alguns, mesmo antes do encargo de cuidar, já apresentavam doenças crônicas. Dois cuidadores têm câncer e estão bem debilitados. O risco de agravamento das doenças decorrente do desgaste relativo às muitas atividades desenvolvidas pelo cuidador de idosos dependentes foi alvo de vários estudos 10,11,12.

Embora cuidar possa ser sofrido, a evolução da doença e a aceitação da nova realidade podem conduzir a mudanças. Alguns cuidadores relatam que passaram por várias etapas e que hoje são outras pessoas.

“Agora eu estou vivendo outra coisa, outro momento. Primeiro eu não aceitava de jeito nenhum e achava injusto o que estava acontecendo comigo e isto me deixava mais cansada, mais esgotada, porque eu achava que ela estava me castigando: 'Agora o seu último castigo é cuidar!' Hoje é diferente, é uma mágica que aconteceu, eu passei a fazer tudo com mais alegria e tudo mudou e ela também mudou. Eu me sinto mais feliz, mais leve, fico cansada ainda, mas é diferente..." (Geórgia, filha, 48 anos).

Como nas entrevistas individuais, as questões sobre o que sentem, que sintomas apresentam, emergiram com constância nas sessões grupais, nas formas mais variadas. No grupo, entretanto, aparece como um pedido de ajuda. É importante chamar a atenção para este fato porque notamos que as experiências internas do cuidador são revistas, pensadas e (re) experimentadas nas sessões. Dessa forma, pudemos mais facilmente perceber as mudanças operadas com as pessoas que cuidam, no decorrer do tempo.

Constatamos, em diversos membros do grupo, mais otimismo, bom humor, alegria, menos angústia, apesar de persistirem sentimentos de tristeza, cansaço, dúvida e medos de várias or- dens. Essas mudanças apontam para a legitimidade do suporte grupal para cuidadores de pessoas idosas com alto nível de dependência.

\section{Significados do ato de cuidar}

A dor, a dificuldade, as preocupações referentes ao ato de cuidar conduzem à busca de um significado para esse ato. É importante significar o sofrimento para aprender e crescer do ponto de vista existencial. Crescimento, gratidão, doação, amor, dever, reparação, obrigação, elaboração de conflitos, resgate de omissões, troca, suprir necessidades de carinho ou de amor, missão, descobrir potencial, aprendizado, vontade de Deus, são significados que os nossos entrevistados deram para o cuidar.

"Cuidar é o crescimento comum, o crescimento espiritual, é ter ímpeto" (Geórgia, filha, 48 anos).

No caso dos cônjuges homens, observamos que eles são muito gratos às mulheres por terem cuidado dos filhos enquanto eles trabalhavam, por terem cuidado da casa. Significar o cuidado como dívida de gratidão, nesses casos, faz-nos pensar que o papel de dona de casa era valorizado e caracteristicamente feminino, denotando, assim, as marcas de uma época 4,9 .

Consideramos que significar o cuidar é um mecanismo de sublimação, por isso eles exaltam, tornam sublime o cuidado. Quando os cuidadores sublimam, seguem adiante com mais facilidade. Os nossos entrevistados mostraram, mais especificamente nesta categoria, a força que têm os preceitos morais e religiosos para significar o cuidar. Os depoentes confirmam pesquisas 10,13 sobre a importância da espiritualidade e da religião para ajudar a enfrentar as dificuldades inerentes ao cuidar, ao mesmo tempo em que ambas dão um sentido à vida. Constatamos, em muitos entrevistados, a necessidade de ter um sentido de vida pautado em seus próprios valores, para interpretarem e avaliarem suas experiências. Significar torna o ato de cuidar um sentido.

Esta categoria apresentou um aspecto curioso na dinâmica grupal. O grupo é como uma caixa de ressonância. A vulnerabilidade de um ecoa na vulnerabilidade do outro. Se um participante está mais fragilizado, os outros ficam angustiados porque deparam com a sua própria fragilidade. Assim, quando eles dão um significado para um companheiro, estão dando para eles também. No grupo de suporte, alguns cuidadores relataram o quanto eles melhoraram como pessoas quando passaram a cuidar. 
História do relacionamento do cuidador com o idoso antes da doença

No grupo estudado, 17 entrevistados disseram ter bom relacionamento com a pessoa cuidada antes da doença. As histórias são longas e detalhadas. Vejamos um fragmento no qual podemos verificar o cuidar como dívida de reciprocidade 14 :

"Bem, como casal nós sempre nos demos bem, eu até falo para ela: 'Se hoje eu tivesse que casar de novo, eu ia casar com você. Mas ela parece que não entende mais o que eu digo. Eu sempre trabalhei muito (...) Quase não parava em casa (...) 'correndo atrás', sabe? Ela que dava conta de tudo, cozinhava muito bem. Eu brinco dizendo que era quase igual à minha mãe. Agora ela não consegue fazer nem a comida. Criou os três filhos, todos os três se formaram (...) Não tinha briga nem confusão. Hoje sou eu que faço tudo para ela..." (Heraldo, esposo, 71 anos).

Os sete cuidadores que relataram conflitos no relacionamento, antes de o familiar adoecer, são filhos. Observamos neles a tentativa de atualização de antigos conflitos, tentativas de reparação e de resgate. Por vezes, a tentativa de resolver antigos conflitos dificulta ver o comportamento do paciente como sintoma da doença, e esses cuidadores dão a impressão de estarem, em parte, vivendo um tempo já passado. No relacionamento familiar, o passado e o presente podem se misturar, sem que seus membros se dêem conta, na tentativa de resolução de antigos conflitos, os quais podem ser até transmitidos intergeracionalmente 5 .

A história do relacionamento mostrou-se bastante importante para compreender não só o surgimento, mas a construção da subjetividade do cuidador, na medida em que ela se faz no relacionamento com a pessoa cuidada. Percebemos que os relacionamentos, anteriormente à doença, já apontavam quem seria o cuidador e como cuidaria.

Esta categoria surgiu nos encontros do grupo de suporte somente quando um participante associava fatos da sua história passada ao relacionamento atual com a pessoa cuidada, ou com os outros familiares. Desse modo, os participantes não se aprofundavam na história do relacionamento, até mesmo porque este não é o objetivo desse tipo de grupo. Nas entrevistas individuais, ao contrário, a história do relacionamento foi o assunto em que os participantes mais se estenderam.

\section{Relacionamento cuidador/idoso} após a doença

O relacionamento do cuidador com o parente cuidado foi descrito como bom, segundo 19 entrevistados. Eles se referem ao esforço para dar carinho, compreender, estimular, embora tenham momentos de impaciência, desânimo e cansaço.

"Eu tenho muito carinho, amor, eu aprendi a dar amor. A minha irmã dá presentes. Tudo dela é o dinheiro. Ela nem liga, ela quer é amor e ela sente (...) A gente pensa que ela não sente, mas ela sente" (Cibele, filha, 47anos).

No entanto, os cuidadores têm dúvidas sobre se estão se relacionando bem ou não com o paciente, e isso ocorre em virtude de suas vivências subjetivas, na medida em que experimentam internamente sentimentos antagônicos e muita culpa, como já vimos. É comum falarem em se dar sem ter retorno. O comportamento agressivo de alguns pacientes, por vezes, exaspera os cuidadores, e estes lamentam por não serem reconhecidos pelo esforço que fazem.

Dentre os filhos com dificuldades no relacionamento com o doente, três falam em episódios de agressão física (sacudidas e tapas) e dois relatam agressão verbal ocasional. Nenhum deles, entretanto, deixa de ser solidário no cuidar, sendo as agressões esporádicas, deixando os agressores muito culpados.

“Eu reajo, reajo sim, porque a gente perde a paciência, ela testa a gente, testa além do limite, porque ela fica agressiva, me irrita, eu fico nervosa..." (Fernanda, filha, 49 anos).

Quando a pessoa se sente obrigada a cuidar, a dívida de reciprocidade desperta sentimentos ambíguos, que podem conduzir à agressão ${ }^{14}$. No entanto, não podemos esquecer que os comportamentos anti-sociais do sujeito demenciado desestabilizam emocionalmente o cuidador, o qual se descontrola reagindo com violência. É possível que este esteja sobrecarregado física e psicologicamente, carecendo de apoio de diferentes ordens. Segundo os depoentes, os relatos de violência ocasional aconteceram em horas de desespero.

Os familiares cuidados também apresentam alterações de humor e têm, algumas vezes, reações intempestivas, violentas, atirando objetos, batendo no cuidador, gritando ou xingando. O apoio da família, dos amigos e dos profissionais é muito importante, principalmente nesses momentos 11,12.

Um aspecto intrigante dentro desta categoria refere-se a como a pessoa cuidada se relaciona com o seu cuidador. A par de todas as dificuldades que possam existir no relaciona- 
mento, e da perda de contato com a realidade, a pessoa que demenciou cria um laço de dependência forte com o cuidador e conta com ele para tudo, não querendo que ninguém mais a acompanhe. Talvez o cuidador seja a única pessoa com quem ela interage e com quem, mesmo com todas as dificuldades que possa ter, busca uma relação pessoal e não uma relação de uma pessoa para com um objeto do diagnóstico.

Diferentemente das entrevistas individuais, cujos relatos apontaram para um relacionamento com poucos conflitos, as situações de impasse aparecem mais nas sessões de grupo. Os participantes se atêm mais aos impasses no grupo porque sabem que ali é o lugar em que eles podem redimensionar e elaborar melhor os conflitos relacionais.

\section{Mudanças na vida do cuidador principal}

Muitas mudanças práticas ocorrem na vida do cuidador 11,15. A adaptação do ambiente físico foi um tema bastante freqüente e abarca a mudança do paciente para a casa do cuidador, a mudança do cuidador para a casa ou para perto do paciente e as reformas para criar um ambiente propício para uma pessoa com demência. Alguns cuidadores sentem-se invadidos com a presença de um acompanhante.

"É aquela gente toda dentro de casa e é comida e é bebida e mudam as coisas de lugar... Eu sei que eu preciso, mas tem hora que me dá vontade de chutar tudo. 'Vai embora, eu não quero mais vocês aqui!' [chora] Parece que a casa não é minha..." (Julieta, esposa, 70 anos).

Os entrevistados enfatizaram também a inversão de papéis, o que implica a mudança de como eles se viam anteriormente. Entretanto, mais do que qualquer outra mudança, e que tem a ver com a mudança de papéis, a preocupação constante com o parente cuidado foi o que os entrevistados abordaram com mais freqüência. Este parece ser um aspecto que desgasta muito os cuidadores e que indica o quanto eles estão circunscritos ao papel que desenvolvem. Pelo fato de as atitudes do paciente serem imprevisíveis e também por as pessoas que cuidam não se tranqüilizarem quando outro está cuidando no seu lugar, elas ficam o tempo todo preocupadas com o que possa estar acontecendo com o parente, alvo dos seus cuidados.

“Tenho um psicólogo que diz: 'Vai, vai ao cinema (...)' Eu sei que todo mundo vai, sai. Me pergunta se eu vou? Não vou, não quero ir, não me interessa. As obrigações que eu tenho eu faço: vou na rua toda hora, vou ao meu médico, mas só de ver ele assim tão paradinho não me dá vontade de fazer mais nada. Minhas filhas falam: 'Mãe, você ainda não se acostumou?' 'Filha, podem passar vinte anos que o meu amor, a minha paixão (...) Eu queria dividir o que ele tem comigo..." (Julieta, esposa, 70 anos).

Nas sessões de grupo, esta categoria deixou mais claros elementos que quase não foram abordados nas entrevistas individuais. Dentre as mudanças na vida pessoal, as perdas econômicas e o relacionamento com um ajudante ou um acompanhante profissional foram bastante comentados, juntamente com as outras mudanças já discutidas na análise desta categoria. Sobre o relacionamento com os acompanhantes foram apontados aspectos positivos por alguns, como a divisão das tarefas, a importância de ser alguém que não está tão envolvido com o portador da doença e o conhecimento técnico para cuidar.

Outros cuidadores referiram-se mais aos aspectos negativos, como os gastos extras, a presença de estranhos em casa, a necessidade de estarem atentos para ver se o acompanhante não vai maltratar o paciente.

\section{Mudanças na família}

A análise desta categoria evidencia os transtornos no relacionamento dos familiares quando um de seus membros adoece. As pessoas lidam com a eclosão e o prosseguimento da doença pautadas por crenças, mitos, normas e papéis estabelecidos, que concorrem para a dinâmica de cada família em particular. Em certas famílias, a regra é dividir as responsabilidades; em outras, é obrigação cuidar dos pais; em outras, os velhos atrapalham, e assim por diante. Considerando a atual pluralidade de modelos de família, as reações são as mais variadas e refletem também as demandas econômicas e sócioculturais.

"Eu e a T. [irmã] sempre fomos assim: uma ajuda a outra. A mamãe ia trabalhar e a gente sempre contou uma com a outra. Mas como eu te disse, a T. não tem dinheiro. Eu ainda ajudo ela. Então eu arco com as responsabilidades $e$ com as despesas. Para você ter uma idéia, este mês só, eu gastei mais de $R \$ 1.500,00$ com a mamãe. Mas a T. me ajuda em tudo. A gente combina, quando uma não pode a outra vai. Agora, o resto da família..." (Fernanda, filha, 49 anos).

Onze entrevistados queixaram-se do afastamento dos outros parentes. As reclamações giravam em torno da falta de participação nas tarefas e de auxílio econômico. Alguns entrevistados já tinham dificuldade no relacionamento com os outros parentes, mas a maioria relata, com surpresa, os impasses que surgiram 
no âmbito da família a partir do momento em que souberam que a pessoa que demenciou precisava ser cuidada.

O sentimento de solidão experimentado pelos cuidadores parece estar ligado ao fato de eles acharem que não devem pedir ajuda, mesmo quando estão assoberbados com as tarefas. Se um membro da família, por características pessoais, oferece ajuda, eles ficam agradecidos, mas não recorrem aos outros familiares.

A mudança no sistema familiar causa crises e pode trazer rupturas. O ritmo de vida da família é atropelado pela doença 16. A adaptação a essa nova situação não se faz imediatamente e, algumas vezes, é necessária a mediação de um profissional.

Quando a rede de interações já é conflituosa antes da doença, ou a harmonia da família deve-se a um contato formal ou distante, ou, ainda, quando nas normas da família não cabem negociações e acordos explícitos, a divisão das tarefas fica mais difícil e surgem ressentimentos e desavenças.

Verificamos nesta categoria aspectos como competição entre os irmãos, disputa pelo amor dos pais, falta de diálogo franco, afastamento de alguns membros, alianças com uns e exclusão de outros parentes. As doenças na família podem desencadear essas questões. O sistema familiar, pela vulnerabilidade de seus membros que ainda não se estabilizaram depois das mudanças de papel e da quebra do equilíbrio, torna-se um terreno fértil para a eclosão de uma verdadeira crise, o que aumenta consideravelmente o risco de disrupção. Esse estágio é temporário, e nas famílias mais saudáveis tende a surgir um outro equilíbrio a médio prazo 17. Percebemos, em mais de metade dos entrevistados, esse estado de crise.

Esta categoria surge no grupo como um dos temas com maior carga emocional. Os conflitos com e entre os familiares, as omissões, o afastamento e as rupturas deixam os cuidadores muito mobilizados. A falta de franqueza para evitar o confronto emocional, a longo prazo, dificulta o ajustamento. Nesses casos, nas terapias familiares, deve ser estimulada a comunicação franca entre as pessoas envolvidas 17 . Nessa ótica, o trabalho no grupo de suporte deve considerar a responsabilidade do cuidador que se cala diante dos demais familiares e se queixa no grupo, questionando sobre as impossibilidades de uma comunicação direta com os parentes e levando-os a compreender que eles também estão se omitindo quando não falam.

\section{Causas para o surgimento da doença}

Esta categoria aponta para uma preocupação intensa de alguns sujeitos com o que teria causado a doença no familiar. Os sujeitos que se mostraram mais objetivos detiveram-se nas dimensões fisiológicas, genéticas e de hereditariedade. Interessam-se por tudo que é publicado sobre o quadro patológico, e a participação de um deles no grupo de suporte é mais no sentido de obter esclarecimentos e de transmitir informações.

"Desde que eu soube que minha mãe estava doente, eu tratei de conhecer tudo sobre o assunto. Já freqüentei vários grupos diferentes, leio tudo que sai sobre Alzheimer. Não adianta ficar só preocupado com o doente, tem que ter conhecimento. Tem que se informar. Eu acho que o que eu posso dar de melhor para a minha mãe é uma pessoa que tenha experiência sobre o assunto. Não adianta a gente cuidar sem saber o que é melhor. Uma enfermeira, por exemplo, pode ajudar muito mais do que eu. Eu não vou deixar de dar atenção, de ver o que ela precisa, mas não sou eu, um leigo, que vou cuidar" (Carlos, filho, 42 anos).

Para esses cuidadores, embora sejam pessoas preocupadas com os parentes que precisam ser cuidados, o conhecimento técnico de um profissional é mais importante para o paciente do que o contato afetivo.

Compreender melhor a doença dá mais segurança, maior senso de controle e aponta para duas direções. Uma delas é ter uma explicação lógica, que não envolva o cuidador, ou seja, a doença nada tem a ver com o relacionamento dele com a pessoa cuidada. A outra direção aponta para a possibilidade de tratamento ou de cura.

$\mathrm{O}$ desejo dos cuidadores de saber por que o seu familiar demenciou toma outra dimensão no contexto do grupo. Acreditamos que, como os coordenadores são profissionais especialistas voltados para a saúde dos idosos e, no imaginário dos participantes, com conhecimento para responder às questões referentes à origem da doença, o grupo torna-se um lugar propício para esse tipo de questionamento 18 .

\section{Considerações finais}

Quando uma síndrome demencial atinge um membro da família, todo o sistema familiar é atingido. Saber quem é o cuidador principal, como e por que ele surge no sistema familiar é um dado importante e carente de investigação.

Os dados revelaram três dimensões muito significativas da questão estudada. A primeira 
delas mostra as implicações dos legados, das transmissões multigeracionais, das repetições dos padrões, dos mitos e das crenças característicos de cada sistema familiar, o que contribui não só para o surgimento do cuidador principal, mas também para o papel que cada membro ocupa dentro da família.

A nova arrumação de papéis, decorrente da mudança no ritmo de vida da família ou do surgimento de uma doença, não se faz sem crise, pois desequilibra a estabilidade familiar, uma vez que são postos em xeque esses mesmos mitos, padrões e crenças.

Assim, vemo-nos diante da necessidade de nos aprofundarmos em estudos transgeracionais com as famílias dos idosos. A verificação de como esses modelos são passados, incorporados e transformados pelo grupo, de forma a manter, ou não, as regras que delimitam determinado sistema familiar, dará maior sustentação ao trabalho com as famílias que tenham idosos sadios ou doentes.

A segunda dimensão destaca o subsistema cuidador/idoso demenciado. Essa dimensão indica que, nesse subsistema, o familiar que é alvo de cuidados também é um participante ativo na decisão de quem vai cuidar dele, ora aceitando, caso o cuidador seja aquele que ele quer, ora reagindo, até que tenha o cuidador que deseja.

Sobre esse aspecto, é importante que sejam revistos os conceitos sobre o idoso demenciado. É preciso escutá-lo e compreendê-lo, para que a relação do cuidador com a pessoa cuidada seja construtiva para ambos. É necessário que os profissionais conheçam e desenvolvam habilidades de comunicação não verbal para dar esse suporte ao cuidador.

A terceira dimensão demonstra o quanto um grupo de suporte, com uma proposta de oferecer recursos para além das informações e esclarecimentos, pode ser importante para os familiares que cuidam de idosos com alto nível de dependência. As sessões gravadas do grupo de suporte reforçaram muitas das colocações feitas nas entrevistas individuais. No contexto do grupo, elas emergem de forma peculiar, tendo em vista a dinâmica própria do processo grupal.

Pelos dados colhidos, neste e em outros estudos, identificamos que a maneira como os familiares cuidam está ligada a como concebem o ato de cuidar. O grupo investigado aponta para as possibilidades de mudança dos participantes, elaborando e (re)significando o cuidado. A elaboração e a (re) significação revertem-se em benefícios para o cuidador, para a pessoa dependente e para os familiares que não estão participando, visto que o relacionamento de quem cuida não muda em uma só direção.

Ao destacar esse último aspecto, consideramos a necessidade de aprofundamento dos estudos referentes ao apoio fornecido na dinâmica grupal. O apoio formal deve incluir os grupos de suporte, e estes carecem de uma fundamentação teórica e metodológica consistentes para assegurar a prática daqueles profissionais que se dispuserem a trabalhar com cuidadores familiares.

\section{Resumo}

O presente estudo tem como objetivo contribuir para uma melhor compreensão do cuidador familiar principal de idosos altamente dependentes. Realizado em uma unidade ambulatorial, utilizou-se o método de análise de conteúdo. Os dados foram colhidos através de entrevista e em 14 sessões de grupo com 24 cuidadores principais de idosos com diagnóstico de demência, emergindo as seguintes categorias: negação versus aceitação da doença antes e depois do diagnóstico; como e por que surge o cuidador principal; características do cuidador; vivências do cuidador; significados do ato de cuidar; história do relacionamento do cuidador com a pessoa cuidada antes da doença; relacio- namento cuidador/idoso após a doença; mudanças na vida do cuidador; mudanças na família; causas para o surgimento da doença. Concluiu-se que existem três dimensões na questão estudada: (1) há implicações dos legados, das transmissões multigeracionais, das repetições dos padrões, dos mitos e das crenças característicos de cada sistema familiar; (2) o idoso também é um participante ativo na decisão de quem vai cuidar dele; (3) o grupo de suporte é um recurso muito importante para os familiares.

Idoso; Cuidadores; Família 


\section{Colaboradores}

T. M. Silveira trabalhou na concepção da pesquisa, na coleta e análise dos dados, na pesquida bibliográfica e na redação. C. P. Caldas trabalhou na redação e revisão do texto. T. F. Carneiro trabalhou na pesquisa.

\section{Referências}

1. Gomes MM. Epidemiologia das desordens demenciais. In: Corrêa AC, organizador. Envelhecimento, depressão e doença de Alzheimer. Belo Horizonte: Health; 1996. p. 25-37.

2. Brand TJ, Rich JB. Memory disorders in the dementias. In: Baddeley AD, Wilson BA, Watts FN, editors. Memory disorders. Nova York: John Wiley \& Sons; 1995. p. 243-70.

3. Bardin L. Análise de conteúdo. Lisboa: Edições 70; 1977.

4. Jablonski B. Até que a vida nos separe: a crise do casamento contemporâneo. Rio de Janeiro: Agir; 1991.

5. Bowen M. Family therapy in clinical practice. New York: Jason Aronson; 1978.

6. Neuburger R. O mito familiar. São Paulo: Summus; 1999.

7. Krom MM. Família e mitos - prevenção e terapia: resgatando histórias. São Paulo: Summus; 2000.

8. Neri AL, Sommerhalder C. As várias faces do cuidado e do bem-estar do cuidador. In: Neri AL, organizador. Cuidar de idosos no contexto da família: questões psicológicas e sociais. Campinas: Alínea; 2002. p. 9-63.

9. Silveira TM. O sistema familiar e os cuidados com pacientes idosos portadores de distúrbios cognitivos. Textos Envelhecimento 2000, 3:13-28.

10. Mendes PBMT. Cuidadores: heróis anônimos do cotidiano [Dissertação de Mestrado]. São Paulo: Pontifícia Universidade Católica de São Paulo; 1995.

11. Caldas CP. Envelhecimento com dependência: responsabilidades e demandas da família. Cad Saúde Pública 2003; 19:773-81.
12. Karsch UM. Envelhecimento com dependência: revelando cuidadores. São Paulo: EDUC; 1998.

13. Velasquez MD. As trajetórias de vida dos cuidadores principais. In: Karsch UM, organizadora. Envelhecimento com dependência: revelando cuidadores. São Paulo: EDUC; 1998. p. 87-145.

14. Zarit SH, Stevens HE, Edwards AB. Caregiving: research and clinical intervention. In: Woods RT, editor. Handbook of the clinical psychology of ageing. Chichester: John Wiley \& Sons; 1996. p. 333-68.

15. Neri AL. Bem-estar e estresse em familiares que cuidam de idosos fragilizados e de alta dependência. In: Neri AL, organizadora. Qualidade de vida e idade madura. Campinas: Papirus; 1993. p. 237-85.

16. Rolland JS. Doença crônica e o ciclo de vida familiar. In: Carter B, McGoldrick M, organizadores. As mudanças no ciclo de vida familiar: uma estrutura para a terapia familiar. $2 \underline{a}$ Ed. Porto Alegre: Artes Médicas; 1995. p. 373-92.

17. Brown FH. O impacto da morte e da doença grave sobre o ciclo de vida familiar. In: Carter B, McGoldrick M, organizadores. As mudanças no ciclo de vida familiar: uma estrutura para a terapia familiar. 2a Ed. Porto Alegre: Artes Médicas; 1995. p. 393-414.

18. Brandão LM. Psicologia hospitalar: uma abordagem holística e fenomenológico-existencial. Campinas: Livro Pleno; 2001.

Recebido em 25/Fev/2005

Aprovado em 06/Dez/2005 